\title{
Satisfaction of Patient in Undergraduate Periodontal Clinic at University of Malaya
}

\author{
Abdul Ghani $\mathrm{M}^{1}$, Mohd Zaki $\mathrm{MH}^{1}$, Cheah $\mathrm{CW}^{2}$ \\ ${ }^{1}$ Faculty of Dentistry, University of Malaya, Kuala Lumpur, Malaysia. \\ ${ }^{2}$ Department of Restorative Dentistry, Faculty of Dentistry, University of Malaya, Kuala Lumpur, Malaysia.
}

\begin{abstract}
The aim of study was to evaluate the level of satisfaction of patients treated in the undergraduate Year 4 and Year 5 of University of Malaya. The subjects were patients treated in the Year 4 periodontology clinic (Polyclinic B) $(n=38)$ and Year 5 periodontology clinic (Polyclinic C) $(n=30)$. Data was gathered using a questionnaire which consisted of 4 components namely appointment facilities, infrastructure and basic facilities, behaviour of students dental clinician, and quality and efficiency of treatment provided. The results showed that for appointment facilities the level of satisfaction was almost $80 \%$; for infrastructure and basic facilities the satisfaction was more than $85 \%$; for behavior of students dental clinician the level of satisfaction was more than $90 \%$ and for quality and efficiency of treatment provided the level of satisfaction was more than $60 \%$. When all the components were compared between patients treated in Polyclinic B to patients treated in Polyclinic C, there was no statistically significant difference $(p>0.05)$. In conclusion, the level of satisfaction of patients treated in the undergraduate Year 4 and Year 5 periodontology clinic of University of Malaya is the same.
\end{abstract}

Keywords: Facilities and infrastructure, patient satisfaction, periodontal treatment, pain, quality of the treatment, undergraduate students.

\section{INTRODUCTION}

Dentistry is a dynamic health profession that requires a comprehensive understanding of a spectrum of healthcare, basic sciences and specific education in oral sciences. The dental institute provides the setting to learn, improve, understand, and adapt the concept of professionalism. At the same time, students also learn to respect, and have compassion for their patients.

Nowadays, people are more aware and concerned about their dental health and quality of dental treatment that they are being provided. Majority of the general public still depends on dental health care centres to resolve their major and minor dental problems. Major concerns from the patients are skills of the dentist and facilities at the centre. Thus, constant investigation is required in order to find out the factors that promote the satisfaction of patients $(1,2,3)$. Evaluation of patient satisfaction can be used to gauge performance of health care system $(1,2)$. Therefore, feedback from patient is an important factor for managers of dental care set-ups to assess and improve quality of services that they provide.

The prevalence of periodontal disease is more than $90 \%$ and $18 \%$ out of this (BPE score 4) require more complex care $(4,5)$. There are few periodontology clinics available around Klang Valley. University of Malaya is one of the teaching 
institutions which provide periodontology treatment in the undergraduate clinics. The treatments are basic therapy, or also known as non-surgical periodontal therapy which includes plaque control, scaling, and root surface debridement and re-evaluation (5).

Previous studies stated that one of the most important factors in level of patient satisfaction is dentist's technique (6). Patients' satisfaction with the treatment they received can be used to measure the quality of care provided by the undergraduate dental students. Satisfaction of patient based on treatment that they received would provide an overview of the level of care given to patients from students. Year 5 dental student clinicians assumed to be more competent and good in clinical skills because they undergo 3 years of clinical training compared to Year 4 dental student clinicians with 2 years of clinical training. Besides that, patients' satisfaction is also affected by the appointment facilities, infrastructures and basic facilities in the dental faculties. Thus, the purpose of this study was to evaluate the level of satisfaction of patients' treated in undergraduate periodontal clinic in Year 4 (Polyclinic B) and Year 5 (Polyclinic C) of University of Malaya.

\section{MATERIALS AND METHODS}

Patients undergoing treatment in undergraduate Year 4 (Polyclinic B) and Year 5 (Polyclinic C) periodontology clinic of University of Malaya were invited to participate in this study. The questionnaires were pretested on 5 selected patients in Polyclinic B. Some modifications were made based on the baseline information gathered. This study was approved by the ethics committees, Faculty of Dentistry, University of Malaya [DFRD1506/0019(U)]. The selections of patients for this study were based on these criteria:

- Treated by Year 4 (Polyclinic B) and Year 5 (Polyclinic C) students in periodontology clinic.

- Patient's treatment has completed at least root surface debridement.

- Patient understood and agreed to the purpose and benefits of this study by completing the written consent.

- Patients completed the questionnaire provided.

In this study, two methods were used to collect the data. Some of the questionnaires were given to the patients in the clinic during their appointment time while some were posted to patients' home addresses. From both methods, we had a total of 68 subjects where 38 patients were treated in Polyclinic $\mathrm{B}$ and 30 patients were treated in Polyclinic C.

The questionnaire had two parts; Part A (background information) and Part B (patient's satisfaction and it was divided into four sections; appointment facilities, infrastructure and basic facilities, behaviour of students dental clinician, and quality and efficiency of treatment provided). Data collected was interpreted and statistically analysed using SPSS Version 12.0.1 for Windows.

\section{RESULT}

\section{Socio-demographic Characteristic}

68 patients completed the questionnaire, of which 38 of them were treated in Year 4 clinic and 30 of them were treated in Year 5 clinic (Table 1). The respondents consisted of Malay (23.5\%), Chinese $(48.5 \%)$, Indian $(22.1 \%)$ and others (5.9\%). Majority of patient's age was between $51-70$ years old. $58.8 \%$ of patients had secondary education level and $41.2 \%$ of them were already retired.

Table 1: Socio-demographic characteristics of patients treated in Polyclinic B and C

\begin{tabular}{lc}
\hline Characteristics & $\mathbf{n}(\%)$ \\
\hline Clinic & $38(55.9 \%)$ \\
Polyclinic B & $30(44.1 \%)$ \\
Polyclinic C & \\
Age & $1(1.5 \%)$ \\
$21-30$ years & $7(10.3 \%)$ \\
$31-40$ years & $6(8.8 \%)$ \\
$41-50$ years & $29(42.6 \%)$ \\
$51-60$ years & $17(25 \%)$ \\
$61-70$ years & $8(11.8 \%)$ \\
71 and above years & \\
Ethnicity & $16(23.5 \%)$ \\
Malay & $33(48.5 \%)$ \\
Chinese & $15(22.1 \%)$ \\
Indian & $4(5.9 \%)$ \\
Others & \\
Gender & $42(61.8 \%)$ \\
Male & $26(38.2 \%)$ \\
Female & \\
Educational Level & $40(58.8 \%)$ \\
Secondary & $8(11.8 \%)$ \\
Diploma & $18(26.5 \%)$ \\
Degree & $2(2.9 \%)$ \\
Master/PhD & \\
Working Status & $23(33.8 \%)$ \\
Employed & $7(10.3 \%)$ \\
Unemployed & $10(14.7 \%)$ \\
Own Business & $28(41.2 \%)$ \\
Retired & \\
\hline & \\
\hline & \\
\hline & \\
\hline &
\end{tabular}




\section{Section A: Appointment Facilities}

Table 2 summarized the patients' satisfaction with regards to appointment facilities. 54 patients $(79.4 \%)$ of the patients were satisfied while $5.9 \%$ were not satisfied in term of easiness to make an appointment at dental faculty. As for punctuality of student clinicians, $97.1 \%(n=66)$ of the patients were satisfied that they were seen on time during appointments. On top of that, $89.7 \%$ of the patients $(n=61)$ were satisfied while $1.5 \%$ not satisfied that treatment was completed efficiently in a timely manner.

Table 2: Appointment facilities

1. It was easy to make an appointment (a1)

\begin{tabular}{lccc}
\hline Clinician & $\begin{array}{c}\text { Satisfied (n, } \\
\%)\end{array}$ & $\begin{array}{c}\text { Neutral } \\
(\mathbf{n}, \%)\end{array}$ & $\begin{array}{c}\text { Not } \\
\text { Satisfied } \\
(\mathbf{n}, \%)\end{array}$ \\
\hline Polyclinic B & 32 & 5 & 1 \\
\hline Polyclinic C & 22 & 5 & 3 \\
Total & $54(79.4 \%)$ & $10(14.7 \%)$ & $4(5.9 \%)$ \\
\hline
\end{tabular}

2. You were seen on time for your appointment (a2)

\begin{tabular}{lccc}
\hline Clinician & $\begin{array}{c}\text { Satisfied } \\
(\mathbf{n}, \%)\end{array}$ & $\begin{array}{c}\text { Neutral } \\
(\mathbf{n}, \%)\end{array}$ & $\begin{array}{c}\text { Not } \\
\text { Satisfied } \\
(\mathbf{n}, \%)\end{array}$ \\
\hline Polyclinic B & 37 & 1 & 0 \\
\hline Polyclinic C & 29 & 1 & 0 \\
\hline Total & $66(97.1 \%)$ & $2(2.9 \%)$ & 0 \\
\hline
\end{tabular}

3. Your dental treatment was completed efficiently in a timely manner (a3)

\begin{tabular}{lccc}
\hline Clinician & $\begin{array}{c}\text { Satisfied } \\
(\mathbf{n}, \%)\end{array}$ & $\begin{array}{c}\text { Neutral } \\
(\mathbf{n}, \%)\end{array}$ & $\begin{array}{c}\text { Not } \\
\text { Satisfied } \\
(\mathbf{n}, \%)\end{array}$ \\
\hline Polyclinic B & 34 & 4 & 0 \\
\hline Polyclinic C & 27 & 2 & 1 \\
Total & $61(89.7 \%)$ & $6(8.8 \%)$ & $1(1.5 \%)$ \\
\hline
\end{tabular}

\section{Section B: Infrastructure and Basic Facilities}

$97.1 \%$ of subjects were satisfied with neatness and cleanliness of the infrastructure and basic facilities. $92.6 \%$ of the patients were satisfied while $1.5 \%$ were not satisfied with the cleanliness of the equipment and instrument. As for temperature and lighting in the clinic, respectively 64 patients (94.1\%) and 67 patients $(98.5 \%)$ felt that they were comfortable enough. The last question in this section which was about the adequacy of seats available, $85.3 \%$ were satisfied while $3.5 \%$ were not satisfied.

Table 3: Infrastructure and basic facilities

1. The clinic area was neat and clean (b1)

\begin{tabular}{lccc}
\hline Clinician & $\begin{array}{c}\text { Satisfied } \\
(\mathbf{n}, \%)\end{array}$ & $\begin{array}{c}\text { Neutral } \\
(\mathbf{n}, \%)\end{array}$ & $\begin{array}{c}\text { Not } \\
\text { Satisfied } \\
(\mathbf{n}, \%)\end{array}$ \\
\hline Polyclinic B & 37 & 1 & 0 \\
Polyclinic C & 29 & 1 & 0 \\
Total & $66(97.1 \%)$ & $2(2.9 \%)$ & 0 \\
\hline
\end{tabular}

2. The equipments and instruments were clean (b2)

\begin{tabular}{lccc}
\hline Clinician & $\begin{array}{c}\text { Satisfied } \\
(\mathbf{n}, \%)\end{array}$ & $\begin{array}{c}\text { Neutral } \\
(\mathbf{n}, \%)\end{array}$ & $\begin{array}{c}\text { Not } \\
\text { Satisfied } \\
(\mathbf{n}, \%)\end{array}$ \\
\hline Polyclinic B & 36 & 2 & 0 \\
Polyclinic C & 27 & 2 & 1 \\
\hline Total & $63(92.6 \%)$ & $4(5.9 \%)$ & $1(1.5 \%)$ \\
\hline
\end{tabular}

3. The temperature in the clinic was comfortable (b3)

\begin{tabular}{lccc}
\hline Clinician & $\begin{array}{c}\text { Satisfied } \\
(\mathbf{n}, \%)\end{array}$ & $\begin{array}{c}\text { Neutral } \\
(\mathbf{n}, \%)\end{array}$ & $\begin{array}{c}\text { Not } \\
\text { Satisfied } \\
(\mathbf{n}, \%)\end{array}$ \\
\hline Polyclinic B & 36 & 2 & 0 \\
\hline Polyclinic C & 28 & 1 & 1 \\
\hline Total & $64(94.1 \%)$ & $3(4.4 \%)$ & $1(1.5 \%)$ \\
\hline
\end{tabular}

4. The lightning in the clinic was sufficient (b4)

\begin{tabular}{lccc}
\hline Clinician & $\begin{array}{c}\text { Satisfied } \\
(\mathbf{n}, \%)\end{array}$ & $\begin{array}{c}\text { Neutral } \\
(\mathbf{n}, \%)\end{array}$ & $\begin{array}{c}\text { Not } \\
\text { Satisfied } \\
(\mathbf{n}, \%)\end{array}$ \\
\hline Polyclinic B & 38 & 0 & 0 \\
\hline Polyclinic C & 29 & 1 & 0 \\
\hline Total & $67(98.5 \%)$ & $1(1.5 \%)$ & 0 \\
\hline
\end{tabular}

5. Number of seats in the waiting area is enough (b5)

\begin{tabular}{lccc}
\hline Clinician & $\begin{array}{c}\text { Satisfied } \\
(\mathbf{n}, \%)\end{array}$ & $\begin{array}{c}\text { Neutral } \\
(\mathbf{n}, \%)\end{array}$ & $\begin{array}{c}\text { Not } \\
\text { Satisfied } \\
(\mathbf{n}, \%)\end{array}$ \\
\hline Polyclinic B & 35 & 3 & 0 \\
Polyclinic C & 23 & 4 & 3 \\
\hline Total & $58(85.3 \%)$ & $7(10.3 \%)$ & $3(4.4 \%)$ \\
\hline
\end{tabular}




\section{Section C: Behaviour of Student Dental Clinician}

Table 4 showed the satisfaction of patients towards the behaviour of student dental clinicians. The percentage of patients being satisfied was slightly higher in the Year 4 clinic as compared to the Year 5 clinic, this is in terms of students' professionalism, gentleness and politeness (100\% vs. 90\%); students' proper attire (97.4\% vs. $93.3 \%$ )' discussion of treatment plan (97.4\% vs. 93.3\%) and students' confidence when carrying out treatment $(92.1 \%$ vs. $86.7 \%$ ). As for whether the students' explanation prior to starting the treatment procedure, all the patients treated in both Year 4 and Year 5 were satisfied.

\section{Section D: Quality and Efficiency of Treatment Provided}

Table 5 showed the patients' satisfaction in terms of quality and efficiency of treatment provided. 63 patients were satisfied with the quality of treatment provided, with $94.7 \%$ and $90 \%$ treated in Year 4 and Year 5 respectively. As for whether the treatment provided was painless, the number of satisfied patient is 42, with $57.9 \%$ from Year 4 clinic compared to $66.7 \%$ from Year 5 clinic respectively. A total of $63(92.6 \%)$ patients will recommend the university service to anyone. Table 6 showed that for all the questions asked to the patients treated in Year 4 and Year 5 undergraduate clinic, there were no statistical difference, $p>0.05$.

Table 4: Behaviour of student dental clinician in Polyclinic B and Polyclinic C

1. The student was professional, gentle and polite (c1)

\begin{tabular}{lccc}
\hline Clinician & $\begin{array}{c}\text { Satisfied } \\
(\mathbf{n}, \%)\end{array}$ & $\begin{array}{c}\text { Neutral } \\
(\mathbf{n}, \%)\end{array}$ & $\begin{array}{c}\text { Not } \\
\text { Satisfied } \\
(\mathbf{n}, \%)\end{array}$ \\
\hline Polyclinic B & 38 & 0 & 0 \\
Polyclinic C & 27 & 2 & 1 \\
Total & $65(95.6 \%)$ & $2(2.9 \%)$ & $1(1.5 \%)$ \\
\hline
\end{tabular}

2. The student was properly attire (c2)

\begin{tabular}{lccc}
\hline Clinician & $\begin{array}{c}\text { Satisfied } \\
(\mathbf{n}, \%)\end{array}$ & $\begin{array}{c}\text { Neutral } \\
(\mathbf{n}, \%)\end{array}$ & $\begin{array}{c}\text { Not } \\
\text { Satisfied } \\
(\mathbf{n}, \%)\end{array}$ \\
\hline Polyclinic B & 37 & 1 & 0 \\
Polyclinic C & 28 & 2 & 0 \\
\hline Total & $65(95.6 \%)$ & $3(4.4 \%)$ & 0 \\
\hline
\end{tabular}

3. The student discussed with you the treatment plan (c3)

\begin{tabular}{lccc}
\hline Clinician & $\begin{array}{c}\text { Satisfied } \\
(\mathbf{n}, \%)\end{array}$ & $\begin{array}{c}\text { Neutral } \\
(\mathbf{n}, \%)\end{array}$ & $\begin{array}{c}\text { Not } \\
\text { Satisfied } \\
(\mathbf{n}, \%)\end{array}$ \\
\hline Polyclinic B & 37 & 1 & 0 \\
\hline Polyclinic C & 28 & 0 & 2 \\
\hline Total & $65(95.6 \%)$ & $1(1.5 \%)$ & $2(2.9 \%)$ \\
\hline
\end{tabular}

4. The student explained prior to starting the treatment procedure (c4)

\begin{tabular}{lccc}
\hline Clinician & $\begin{array}{c}\text { Satisfied } \\
(\mathbf{n}, \%)\end{array}$ & $\begin{array}{c}\text { Neutral } \\
(\mathbf{n}, \%)\end{array}$ & $\begin{array}{c}\text { Not } \\
\text { Satisfied } \\
(\mathbf{n}, \%)\end{array}$ \\
\hline Polyclinic B & 38 & 0 & 0 \\
Polyclinic C & 30 & 0 & 0 \\
Total & $68(100 \%)$ & 0 & 0 \\
\hline
\end{tabular}

5. The student was confident when carrying out treatment (c5)

\begin{tabular}{lccc}
\hline Clinician & $\begin{array}{c}\text { Satisfied } \\
(\mathbf{n}, \%)\end{array}$ & $\begin{array}{c}\text { Neutral } \\
(\mathbf{n}, \%)\end{array}$ & $\begin{array}{c}\text { Not } \\
\text { Satisfied } \\
(\mathbf{n}, \%)\end{array}$ \\
\hline Polyclinic B & 35 & 3 & 0 \\
Polyclinic C & 26 & 2 & 2 \\
\hline Total & $61(89.7 \%)$ & $5(7.4 \%)$ & $2(2.9 \%)$ \\
\hline
\end{tabular}

Table 5: Quality and efficiency of treatment provided

1. You were satisfied with the quality of treatment provided (d1)

\begin{tabular}{lccc}
\hline Clinician & $\begin{array}{c}\text { Satisfied } \\
(\mathbf{n}, \%)\end{array}$ & $\begin{array}{c}\text { Neutral } \\
(\mathbf{n}, \%)\end{array}$ & $\begin{array}{c}\text { Not } \\
\text { Satisfied } \\
(\mathbf{n}, \%)\end{array}$ \\
\hline Polyclinic B & 36 & 2 & 0 \\
Polyclinic C & 27 & 2 & 1 \\
Total & $63(92.6 \%)$ & $4(5.9 \%)$ & $1(1.5 \%)$ \\
\hline
\end{tabular}

2. The treatment was painless (d2)

\begin{tabular}{lccc}
\hline Clinician & $\begin{array}{c}\text { Satisfied } \\
(\mathbf{n}, \%)\end{array}$ & $\begin{array}{c}\text { Neutral } \\
(\mathbf{n}, \%)\end{array}$ & $\begin{array}{c}\text { Not } \\
\text { Satisfied } \\
(\mathbf{n}, \%)\end{array}$ \\
\hline Polyclinic B & 22 & 16 & 0 \\
\hline Polyclinic C & 20 & 10 & 0 \\
\hline Total & $42(61.8 \%)$ & $26(38.2 \%)$ & 0 \\
\hline
\end{tabular}


3. You will recommend the university service to anyone (d3)

\begin{tabular}{lccc}
\hline Clinician & $\begin{array}{c}\text { Satisfied } \\
(\mathbf{n}, \%)\end{array}$ & $\begin{array}{c}\text { Neutral } \\
(\mathbf{n}, \%)\end{array}$ & $\begin{array}{c}\text { Not } \\
\text { Satisfied } \\
(\mathbf{n}, \%)\end{array}$ \\
\hline Polyclinic B & 36 & 2 & 0 \\
Polyclinic C & 27 & 3 & 0 \\
Total & $63(92.6 \%)$ & $5(7.4 \%)$ & 0 \\
\hline
\end{tabular}

Table 6: Comparison between the respondents answers from Poly B and Poly C.

\begin{tabular}{|c|c|c|}
\hline No & Question & $p$ value \\
\hline 1 & It was easy to make an appointment? & 0.380 \\
\hline 2 & $\begin{array}{l}\text { You were seen on ti me for your } \\
\text { appointment? }\end{array}$ & 0.865 \\
\hline 3 & $\begin{array}{l}\text { Your dental treatment was completed } \\
\text { efficiently in a timely manner? }\end{array}$ & 0.461 \\
\hline 4 & The clinic was neat and clean? & 0.865 \\
\hline 5 & $\begin{array}{l}\text { The equipment and instrument were } \\
\text { clean? }\end{array}$ & 0.506 \\
\hline 6 & $\begin{array}{l}\text { The temperature in the clinic was } \\
\text { comfortable? }\end{array}$ & 0.494 \\
\hline 7 & The lightning in the clinic was sufficient? & 0.257 \\
\hline 8 & $\begin{array}{l}\text { Number of seats in the waiting area is } \\
\text { enough? }\end{array}$ & 0.093 \\
\hline 9 & $\begin{array}{l}\text { The students is professional, gentle and } \\
\text { polite }\end{array}$ & 0.137 \\
\hline 10 & The student was properly attire? & 0.421 \\
\hline 11 & $\begin{array}{l}\text { The student discussed with you the } \\
\text { treatment plan? }\end{array}$ & 0.187 \\
\hline 12 & $\begin{array}{l}\text { The student explained prior to starting the } \\
\text { treatment procedure? }\end{array}$ & - \\
\hline 13 & $\begin{array}{l}\text { The student was confident when carrying } \\
\text { out the treatment? }\end{array}$ & 0.269 \\
\hline 14 & $\begin{array}{l}\text { You were satisfied with the quality of the } \\
\text { treatment provided? }\end{array}$ & 0.506 \\
\hline 15 & The treatment was painless? & 0.460 \\
\hline 16 & $\begin{array}{l}\text { You will recommend the university service } \\
\text { to anyone? }\end{array}$ & 0.457 \\
\hline
\end{tabular}

\section{DISCUSSION}

In this study majority of patient's age was between 51-70 years old and this was also reported by the previous study that the periodontal disease specifically in chronic periodontitis was highest in the $65-74$ age groups (7). $51 \%$ of the 68 subjects comprised of the unemployed and retired. According to Mohd-Dom et al, income level influenced the Oral Health Quality of Life especially the lower income group as they may have high risk of periodontal disease such as diet, chronic disease, smoking, and habits (7).

Investigating the patients' perception in the quality of the dental services and their perception may provide useful information to develop more comprehensive services (1). In Malaysia, many patients nowadays are aware of their dental health and there is an increased in the demand in dental health services. Moreover, most of the Malaysians had utilised the public sector facilities (5). University of Malaya is one of the oldest schools of dentistry in Malaysia and patient's expectations from the treatment given by the clinical staff/dental students clinicians would assume to be higher. So, patients' satisfaction is the best tools to measure the quality of dental care and it can act as a baseline to improve the quality of dental services especially in Faculty of Dentistry, University of Malaya. Two distinct aspects were evaluated in this study, general facilities and interpersonal skills of the clinician.

All facilities provided will influence patients' satisfaction towards treatments given $(5,2,3)$. The main complaint of patient was that the number of seats at waiting area are not enough especially in Polyclinic C compared to Polyclinic B $(p=0.093)$. After registration and oral screening, patients must wait according to the type of case, severity and also number of case before dental student clinicians called to make an appointment with them. Basically, the 'waiting time' in the public sector and learning centre were longer if compared with private sector (5). In private sector, they work with flexible and convenient hour. Time management in private clinic was not strict as in public dental clinic especially in learning centre. Generally, patients were satisfied with time management of dental student clinician to complete the treatment for them. However, one of the subjects complained that the time taken to complete for one case was too long, as the student needed to get approval from a lecturer before they could proceed to the next part.

Condition of the clinic itself also influences the perception of patient toward the treatment given by the dental student clinicians. According to study done by Adebayo et al, patients were worried about the cross infection especially the disease that normally transmitted through dental procedure such as tuberculosis, hepatitis B and HIV. The cleanliness of the instrument, arrangement and 
handling of the instrument would make patients more confident in treatment given especially the newbie in dental procedure (6). Although doing root surface debridement procedure was a brand new hands-on experience for Year 4 dental clinicians, there was no significant difference regarding the quality of treatment as compared to Year 5 dental clinicians as perceived by the patients. It maybe the exposure to students regarding handling of instruments and management of the working area given were enough in their second year learning. So, the null hypothesis was accepted that there was no different in patients' satisfaction between patients treated by Year 4 compared to patients treated by Year 5 .

Communication process between patient and dental student clinician played an important role in order to achieve the best treatment outcome (8). In the present study, the patients were satisfied with behaviours, communication skills and also clinical skills of their clinicians. Majority of the dental student clinicians explained and discussed with their patient first prior finalising the treatment plan. This was a good way to get the patients to be involved in decision making and share the responsibility in achieving better oral health.

More than $90 \%$ of the patients were satisfied with the quality of the treatment provided but only $1.5 \%$ was not satisfied with it. These patients were treated in Polyclinic $\mathrm{C}$ and there might be intrinsic and extrinsic factors that influenced the satisfaction of these patients. Quality of treatment did not only depend on experience of clinicians but also the physical and mental status of the clinician (9). Based on the previous study, Year 5 students were more stressed compared to the Year 4 because they needed to complete all the requirements before they could sit for the final year professional examination which would influence the quality of services provided to the patients and dental students at University Malaya were more stressed compared to other dental schools in Malaysia (10). Previous study reported that most of the patients were satisfied with the infrastructure but not in pain management and it also was stated that pain management was the important part of handling patient in clinic (11). Only $61.8 \%$ of patients were very satisfied with the painless treatment. In dentistry, pain management is the enemy to the dentist because it will lead to anxiety to the patient and indirectly will decrease the patient's compliance. So, students would need to develop or enhance their clinical skills to provide painless treatment by using physical treatment, pharmacotherapy, cognitive/behavioural methods, and complementary or alternative therapy (12). As a result, all treatments could probably be done with minimal or without any complaint of pain.

In this study, there were some limitations in term of the number of respondents and also time provided to complete the study. Besides that the questionnaire should have also provided a column for the participants to list down complaints other than those listed. Hence, for future studies, the number of subjects needs to be increased and perception from the student dental clinicians can also be evaluated in order to improve the quality of teaching and services of the faculty.

\section{CONCLUSION}

Finding of this study indicate that patients were satisfied with the treatment provided in both Polyclinic $B$ and $C$. There was no significant different in patients' satisfaction between those treated in Year 4 compared to those treated in Year 5. The willingness of patients to recommend the faculty service to the others shows the trust and satisfaction towards all the facilities components in this faculty.

\section{ACKNOWLEDGEMENT}

The authors would like to thank to Registration Department of Faculty of Dentistry, University of Malaya for providing us the basic information of patient.

\section{DECLARATION OF INTEREST}

The authors report no conflicts of interest. The authors alone are responsible for the content and writing of the paper.

\section{REFERENCES}

1. Arejaie AS, Nawasrah AM, Khan SQ, Farooqi FA, Somali R, Al-Mudani WF. Patients' perception toward various dental treatments provided in the internship program. Saudi medical journal. 2014; 35(12): 1513.

2. Adebayo, ET; Adesina, BA; Ahaji, LE; Hussein, NA. Patient assessment of the quality of dental care services in Nigerian hospital. Journal of Administration. 2014; 3(6): 20-28.

3. Newsome, PRH; Wright, GH. A review of patient satisfaction: 2. Dental patient satisfaction: an 
appraisal of recent literature. British Dental Journal. 1999; 186(4): 166-170.

4. Raman R, Freeda Woon TK, Mamat M, Ishak A. Oral health awareness, behaviour and status among Malaysian 16-year-old school students in Penang. 2012, Vol. 34, Issue 2.

5. Oral Health Division, Ministry of Health Malaysia. National Oral Health Survey of Adults 2000 (NOHSA 2000). Oral health status, impact and treatment needs of Malaysian adults. 2004.

6. Janda S, Wang Z, Rao C. Matching dental offerings with expectations. Marketing Health Services. 1996; 16(2): 38.

7. Mohd-Dom TN, Abdul-Muttalib K, Ayob R, Lan YS, Mohd-Asadi AS, Abdul-Manaf MR, et al. Periodontal status and provision of periodontal services in Malaysia: trends and way forward. Journal of Public Health Medicine. 2013; 13(2): 38-47.

8. Schouten B, Hoogstraten J, Eijkman M. Dutch dental patients on informed consent: knowledge, attitudes, self-efficacy and behaviour. Patient education and counseling. 2002; 46(1): 47-54.

9. Dollard M, Winefield HR, Winefield AH. Occupational stress in the service professions: CRC Press; 2003.

10. Saub R, Rajesh S, Muirhead V, Mohd T, Dom $N$, Jamaludin M. Perceptions of Dental Stress and Social Support Among Malaysian Dental Students. Annals of Dentistry of the University of Malaya. 2013; 20(1): 1-7.

11. Chauhan A, Priya H, Kumar M. Factors affecting dental satisfaction among Malaysian dental students. International Journal of Dental Clinics. 2011; 3(2): 5-8.

12. The Role of Opiods in the Management of Acute and Chronic Pain in Dental Practice. Royal College of Dental Surgeon of Ontario. 2014. 1-15.

\section{Corresponding author:}

\section{Dr Cheah Chia Wei}

Department of Restorative Dentistry, Faculty of Dentistry, University of Malaya, 50603, Kuala Lumpur, Malaysia.

Tel: +603-79674883

E-mail Address: chiawei@um.edu.my 